\title{
Stepping Up Active Transportation in Community Health Improvement Plans: Findings From a National Probability Survey of Local Health Departments
}

\author{
Meera Sreedhara, Karin Valentine Goins, Christine Frisard, \\ Milagros C. Rosal, and Stephenie C. Lemon
}

\begin{abstract}
Background: Local health departments (LHDs) are increasingly involved in Community Health Improvement Plans (CHIPs), a collaborative planning process that represents an opportunity for prioritizing physical activity. We determined the proportion of LHDs reporting active transportation strategies in CHIPs and associations between LHD characteristics and such strategies. Methods: A national probability survey of US LHDs ( $<500,000$ residents; 30.2\% response rate) was conducted in 2017 $(\mathrm{n}=162)$. LHDs reported the inclusion of 8 active transportation strategies in a CHIP. We calculated the proportion of LHDs reporting each strategy. Multivariate logistic regression models determined the associations between LHD characteristics and inclusion of strategies in a CHIP. Inverse probability weights were applied for each stratum. Results: $45.6 \%$ of US LHDs reported participating in a CHIP with $\geq 1$ active transportation strategy. Proportions for specific strategies ranged from 22.3\% (Safe Routes to School) to 4.1\% (Transit-Oriented Development). Achieving national accreditation (odds ratio [OR] $=3.67 ; 95 \%$ confidence interval [CI], 1.11-12.05), pursuing accreditation $(\mathrm{OR}=3.40 ; 95 \% \mathrm{CI}, 1.25-9.22)$, using credible resources $(\mathrm{OR}=5.25 ; 95 \% \mathrm{CI}, 1.77-15.56)$, and collaborating on a Community Health Assessment $(\mathrm{OR}=4.48$; 95\% CI, 1.23-16.29) were associated with including a strategy in a CHIP after adjusting for covariates. Conclusions: CHIPs are untapped tools, but national accreditation, using credible resources, and Community Health Assessment collaboration may support strategic planning efforts to improve physical activity.
\end{abstract}

Keywords: physical activity, community health planning, public health systems research

Active transportation provides the opportunity to achieve recommended amounts of physical activity (PA) and is linked to reductions in adverse cardiovascular outcomes. ${ }^{1,2}$ However, a small proportion of US adults and children report walking or biking for transportation. ${ }^{3,4}$ Evidence-based policy, systems, and environmental approaches can increase opportunities for PA by changing land use and transportation systems in communities. ${ }^{5}$

The Community Preventive Services Task Force recommends increasing PA through a combination of land use and transportation policies, designs, or projects that improve the built environment based on the findings from a systematic review. ${ }^{5}$ One such strategy is the development of mixed-use neighborhoods, characterized by a diverse set of destinations (eg, residential, commercial, and open

(C) 2019 The Authors. Published by Human Kinetics, Inc. This is an Open Access article distributed under the terms of the Creative Commons AttributionNonCommercial-NoDerivatives 4.0 International License, CC BY-NC-ND 4.0, which permits the copy and redistribution in any medium or format, provided it is not used for commercial purposes, no modifications are made, and appropriate credit is given. See http://creativecommons.org/licenses/by-nc-nd/4.0. This license does not cover any third-party material that may appear with permission in the article. For commercial use, permission should be requested from Human Kinetics, Inc., through the Copyright Clearance Center (http://www.copyright.com).

Sreedhara, Valentine Goins, Frisard, Rosal, and Lemon are with the Division of Preventive and Behavioral Medicine, Department of Population \& Quantitative Health Sciences, University of Massachusetts Medical School, Worcester, MA, USA. Sreedhara is also with Clinical \& Population Health Research PhD Program, Graduate School of Biomedical Sciences, University of Massachusetts Medical School, Worcester, MA, USA. Lemon (Stephenie.Lemon@ umassmed.edu) is corresponding author. space) within a neighborhood. ${ }^{6}$ Transit-Oriented Development encourages mixed use to enhance the diversity and proximity of destinations near public transit. ${ }^{7}$ Individuals using public transit often walk or bike to transit stops, and expanding services, locations, and connections can improve access and opportunities for PA. 5,8 Traffic safety and injury prevention through road safety audits, speed management, and increased injury surveillance and analysis can foster safer walkable communities. ${ }^{9}$ Safe Routes to School also aims to increase active commuting to school through enforcing safety as well as education and engineering changes. ${ }^{10}$ Smart Growth and Healthy Community design principles recommend combining multiple strategies to promote healthier communities. ${ }^{11,12}$ These strategies also include economic, environmental, and safety cobenefits. ${ }^{13}$ Although communities possess responsibility for the built environment, creating activity-friendly environments requires action by multiple sectors including municipal (eg, transportation, public works, parks and recreation, land-use planning, and health) and nonmunicipal (eg, community-based organizations, advocates, businesses, hospitals, and residents) entities. ${ }^{14}$

A small body of literature reports that few communities have adopted evidence-based active transportation approaches, which indicates room for improvement. ${ }^{15-17}$ In 2015, 25.2\% of US municipalities had a Complete Streets policy, which supports a comprehensive approach to make streets safer for all users, but specific land use or transportation strategies were not identified. ${ }^{15}$ In addition, most such policies have no implementation plan. Among $89.0 \%$ of US municipalities reporting having any type of community plan (ie, comprehensive/general, land use, transportation or bicycle/pedestrian plans), 53.9\% reported street connectivity objectives, and $66.8 \%$ mixed-use objectives. ${ }^{17}$ Complex 
strategies aiming to develop compact, mixed use, walkable neighborhoods face a set of fiscal, organizational, and political barriers (eg, lack of community support). ${ }^{18}$ In addition, municipal officials report lack of intergovernmental collaboration as a barrier to considering PA in community design and layout. ${ }^{19}$

The development of collaborations is a cornerstone of the Community Health Improvement Plan (CHIP) process, which represents a promising long-term strategic health planning approach to address complex public health issues such as physical inactivity. ${ }^{20}$ In 1997, the Institute of Medicine recommended the CHIP process as an effective performance monitoring program to improve community health. ${ }^{21}$ The Public Health Accreditation Board now requires CHIP participation for local health department (LHD) accreditation and recommends that the CHIP considers social determinants of health, policy changes, and evidence-based strategies in response to community health needs. ${ }^{22}$ The CHIP process may catalyze built environment changes to improve PA because collaborations among community stakeholders can generate shared goals and responsibilities while leveraging resources and guiding allocation, all of which is vital in an era characterized by reduced funding and resources for public health activities. ${ }^{20,22,23}$ However, no study has evaluated active transportation strategies included in CHIPs.

Local health departments are primed to play an important role in promoting active transportation, and key stakeholders describe LHDs as providing valuable contributions for PA policy decision making (eg, emphasizing health impacts of built environment policies, data analysis, and developing partnerships) ${ }^{24}$ that may benefit the CHIP process. However, only $25 \%$ of US LHDs participate in community-level urban design or land use policy and advocacy activities, and fewer (16\%) participate in active transportation activities. ${ }^{25}$ Previous literature from our team and others have identified LHD characteristics associated with PA policy involvement. ${ }^{26}$ Literature describes smaller LHDs serving $<50,000$ residents as having less capacity to provide essential public health services related to obesity prevention and less participation in PA policy/advocacy activities as compared with large LHDs $(\geq 500,000) .25,26$ Therefore, CHIPs may help smaller LHDs increase capacity by engaging more partners. ${ }^{27}$ While LHDs with a state or shared governance structure or location in the Northeast or South were less likely to report participating in active transportation policy activities, those engaging in performance improvement efforts (ie, CHIP development and Public Health Accreditation Board accreditation) were more likely. ${ }^{25}$ This may occur because accreditation sharpens LHD focus on policy work and evidence-based strategies. ${ }^{25}$ However, this body of literature is small, and research assessing characteristics of LHDs reporting active transportation strategies included specifically within CHIPS has yet to be conducted.

The objective of this study was to determine the proportion of US LHDs reporting any of 8 evidence-based active transportation strategies in a CHIP. In addition, we assessed the association of LHD characteristics with the inclusion of at least one such strategy in a CHIP.

\section{Methods}

\section{Study Design}

A web-based, cross-sectional national probability survey of US LHDs, conducted from June to October 2017, was one activity within a larger research program focused on understanding and increasing the engagement of public health in land use and transportation. The research program is part of the Physical
Activity Policy Research Network Plus, which is a Center for Disease Control and Prevention-funded research network aimed at advancing PA policy research. The University of Massachusetts Medical School Institutional Review Board approved this study.

\section{Description of Sample}

Local health department officials were eligible to participate as a representative of their US LHD if they were Directors or a held similar position and their LHD served $<500,000$ residents. A random sample of 693 US LHDs was selected from a comprehensive list of US LHDs and Directors maintained by the National Association of County and City Health Officials, an organization that supports and represents LHDs across the United States. The sample was drawn using a proportionate stratified sampling design. Strata were defined by US Census geographic region (Northeast, Midwest, South, and West) and population size served $(<40,000$ or 40,000-499,999).

\section{Description of Survey Development and Administration}

Survey questions about LHD involvement and capacity to participate in evidence-based active transportation policy decision making were developed after a review of the literature and feedback from Physical Activity Policy Research Network Plus colleagues. Survey questions were cognitively tested ${ }^{28}$ among LHD practitioners $(n=5)$. Qualtrics software (Qualtrics, Provo, UT, October 2017) was used to build the web-based survey, and the research team tested the timing and usability of the web-based format. The time to complete the survey was estimated to be 10 to 20 minutes.

We followed a standardized survey administration protocol. The LHD sample received personalized e-mail invitations with a unique link to the web-based survey that included an introduction and instructions. A response to the survey served as consent to participate. Participants were offered the opportunity to enter a raffle for completion. Nonrespondents received an e-mail reminder after 1 week, telephone reminders during weeks 2 and 3, and telephone messages at the third call. Participants who agreed during a reminder call to do the survey but then did not complete it were sent a reminder e-mail with the survey link. Upon request, surveys were resent or was sent to another knowledgeable individual within the LHD. We provided telephone administration to 4 participants who were unable to receive the web-based survey through their organizational e-mail.

\section{Measures}

CHIP Status. Response options to the question: "Has your local health department participated in developing a Community Health Improvement Plan?" were, "Yes, within the last three years"; "Yes, more than three but less than five years ago"; "Yes, five or more years ago"; "No, but plan to in the next year"; "No"; or "Don't know." We subsequently generated a new dichotomous variable to align with Public Health Accreditation Board's requirement of LHDs seeking accreditation to provide a CHIP dated within 5 years. ${ }^{22}$ Responses of “don't know" were coded as missing.

LHD Characteristics. We evaluated several LHD characteristics identified in the literature as important for PA policies. ${ }^{25,26,29}$ The characteristics included population size served, ${ }^{25,26}$ structure, ${ }^{25,26}$ Public Health Accreditation Board status, ${ }^{25}$ Community Health Assessment status, ${ }^{25}$ engagement with nonprofit hospital on Community Health Assessment, use of credible resources, ${ }^{29}$ US Census 
geographic region, ${ }^{25}$ and governance. ${ }^{25,26}$ Population size served was initially determined by LHD responses to the question "What is the approximate size of your local health department's service area?" The five response options were $<25,000,25,000-49,999$, 50,000-99,999, 100,000-249,999, 250,000-499,999 and the latter 2 were collapsed due to small cell sizes. Structure was assessed as a 7-category variable and recategorized due to small cell sizes. The final structure categories were municipal, county or city-county, and other (including regional, state-run, public health network, or other) health departments. LHD status in the Public Health Accreditation Board's accreditation program was evaluated as an 8-category variable, and we recoded it as a 3-category variable of achieved accreditation, in progress or planned, and not accredited. Community Health Assessment completion status was asked as a 6-category variable and then recoded similar to the CHIP status variable based on Public Health Accreditation Board guidance on Community Health Assessments into a dichotomous variable of "Yes, within the last five years" or "No, or five or more years."22 LHDs were asked to describe the extent of the LHD's engagement with nonprofit hospitals on a Community Health Assessment, and response options were recoded into a categorical variable of "Yes, current or past collaboration," "No current or past collaboration." LHDs reported on 8 resources used to guide inclusion of policy strategies in the CHIP, from which a categorical variable was generated as "Yes, the Community Guide, National Prevention Strategy or Healthy People 2020 were used" or "No, did not use credible resource." For this variable, LHDs that did not participate in a CHIP within the past 5 years were recoded as not using credible resource in a CHIP in the past 5 years.

We used administrative records from the National Association of County and City Health Officials for 2 variables. US Census geographic region was assessed as Midwest, Northeast, South, and West. States were classified using the Association of State and Territorial Health Officials definition to generate a state and LHD governance variable, which was dichotomized due to small cell size as "centralized, shared, or mixed" or "decentralized." 30

Outcomes. The outcomes in this analysis were LHD report of inclusion in a CHIP of 8 evidence-based strategies that support active transportation and PA: traffic safety and injury prevention, traffic-related injury surveillance and data analysis, Safe Routes to School, transit access, mixed land use neighborhoods, TransitOriented Development, Smart Growth, and Healthy Community design. ${ }^{5,9}$ LHDs were asked to report if each of the 8 strategies was included in a CHIP within the past 5 years. Each specific strategy was recoded as "not included in a CHIP" if the LHD did not participate in a CHIP within the past 5 years. A dichotomous summary variable was created to indicate that at least one of these 8 strategies was included in a CHIP or not.

\section{Statistical Analysis}

To produce nationally representative estimates, inverse probability sampling weights were generated and applied for each stratum. The weights accounted for the stratified simple random sampling design, differential response rates, and analysis of surveys with complete data on CHIP status, covariates, and outcomes by strata. First, the sampling probability for each stratum was calculated by dividing the number of LHDs sampled in each stratum by the total number of US LHDs in that stratum. Second, the response probability was calculated by dividing the number of survey respondents in each stratum by the number of LHDs sampled in each stratum. Third, the completion probability was calculated by dividing the number of LHDs with complete responses for CHIP status, covariates, and outcome data by the total number of survey respondents for each stratum. For each stratum, the realized sampling probability was the production of LHD-level sampling probability, response probability, and completion probability. We calculated the inverse of the realized sampling probability to generate the final weights used in statistical analyses. We proportionally trimmed the final weights to reflect the true population of US LHDs serving $<500,000$ residents $(n=2390)$.

Local health departments were eligible for this analysis if they had complete data on CHIP status, LHD characteristics, and each of the 8 outcome measures. We conducted 2 sensitivity analyses to compare LHD responders and nonresponders and LHDs with complete data against those with incomplete data using chi-square tests to assess nonresponse and selection bias. Continuous variables were summarized as weighted means. Categorical LHD characteristics and active transportation strategies were calculated as weighted frequencies, proportions, and 95\% confidence intervals (CIs). A logistic regression model was developed to assess which LHD characteristics were associated with the presence of at least one of the 8 evidence-based active transportation strategies in a CHIP. An iterative process identified the following covariates that changed the regression coefficient by $10 \%$ and were included in the final model: size of population served, structure, state and LHD governance, accreditation status, engagement with hospital on Community Health Assessment status, used credible resource, and US Census geographic region. ${ }^{31} \mathrm{We}$ did not include Community Health Assessment status in the development of the model because of lack of variability in responses. Collinearity was evaluated using a cutoff point of variance inflation factors $(>10)$. Model fit was assessed using the Hosmer-Lemeshow test. We used Stata for all analyses (version 13.1; StataCorp LP, College Station, TX).

\section{Results}

The survey response rate was 30.2\% (209/693). Of the LHDs that completed the survey, we excluded LHDs missing data on CHIP status $(n=12)$, outcomes $(n=19)$, and any covariates $(n=16)$. The final analytic sample of 162 LHDs represents 2390 US LHDs. Sensitivity analyses, comparing LHD responders and nonresponders, and LHDs with complete data against those with incomplete data, found no statistically significant differences between these groups with respect to LHD jurisdiction, governance, geographic region, and population size served, indicating limited nonresponse or selection bias.

Two-thirds of the US LHDs in this sample served populations of $\leq 49,999$ residents, and $36.1 \%$ were in the Midwest. A large proportion were county-based or city-county $(70.4 \%)$ and had a decentralized structure (77.7\%). Most LHDs were not accredited by the Public Health Accreditation Board (57.5\%), but had completed a Community Health Assessment (87.9\%) and collaborated with one or more nonprofit hospitals on a Community Health Assessment (75.9\%). Two-thirds of LHDs reported using a credible resource to guide the selection of policies in a CHIP $(64.0 \%)$ (Table 1).

Fewer than half of all US LHDs reported participating in a CHIP within the past 5 years that included at least one evidencebased active transportation strategy (45.6\%; 95\% CI, 37.2\%$54.3 \%)$. The proportion of US LHDs reporting inclusion of each of the 8 specific active transportation strategies ranged from $22.3 \%$ (95\% CI, $15.9 \%-30.5 \%$ ) for Safe Routes to School to $4.1 \%$ for Transit-Oriented Development (95\% CI, 1.7\%-9.6\%) (Table 2). 
Table 1 Characteristics of Participating LHDs $(n=162$ Unweighted; $\mathbf{n}=\mathbf{2 3 9 0}$ Weighted)

\begin{tabular}{|c|c|}
\hline Characteristics & US LHDs, \% \\
\hline \multicolumn{2}{|l|}{ Size of population served } \\
\hline$<25,000$ & 37.0 \\
\hline $25,000-49,999$ & 28.8 \\
\hline $50,000-99,999$ & 16.3 \\
\hline $100,000-499,999$ & 17.9 \\
\hline \multicolumn{2}{|l|}{ US Census geographic region } \\
\hline Midwest & 36.1 \\
\hline Northeast & 24.1 \\
\hline South & 28.4 \\
\hline West & 11.4 \\
\hline \multicolumn{2}{|l|}{ Structure } \\
\hline $\begin{array}{l}\text { Municipal (city or town) health } \\
\text { department }\end{array}$ & 21.1 \\
\hline $\begin{array}{l}\text { County and city-county health } \\
\text { department }\end{array}$ & 70.4 \\
\hline $\begin{array}{l}\text { Other (including state-run and } \\
\text { regional) }\end{array}$ & 8.5 \\
\hline \multicolumn{2}{|l|}{ State and LHD governance } \\
\hline Centralized, shared, or mixed & 22.4 \\
\hline Decentralized & 77.7 \\
\hline \multicolumn{2}{|c|}{ Public Health Accreditation Board accreditation status } \\
\hline Achieved accreditation & 17.9 \\
\hline In progress or planned & 24.7 \\
\hline Not accredited & 57.5 \\
\hline \multicolumn{2}{|c|}{ Community Health Assessment completion status } \\
\hline Yes, within the last $5 \mathrm{y}$ & 87.9 \\
\hline No, or 5 or more years ago & 12.1 \\
\hline \multicolumn{2}{|l|}{ CHIP status } \\
\hline $\begin{array}{l}\text { Yes, participated in CHIP } \\
\text { within } 5 \mathrm{y}\end{array}$ & 75.5 \\
\hline $\begin{array}{l}\text { No, participation in CHIP } \\
\text { within } 5 \mathrm{y}\end{array}$ & 24.5 \\
\hline \multicolumn{2}{|c|}{$\begin{array}{l}\text { Engagement with nonprofit hospitals on a Community Health } \\
\text { Assessment }\end{array}$} \\
\hline $\begin{array}{l}\text { Yes, current or past collabora- } \\
\text { tion with one or more nonprofit } \\
\text { hospitals }\end{array}$ & 75.9 \\
\hline $\begin{array}{l}\text { No, current or past collabora- } \\
\text { tion with one or more nonprofit } \\
\text { hospitals }\end{array}$ & 24.1 \\
\hline \multicolumn{2}{|c|}{ Use of credible resources to guide inclusion of policy strategies in CHIP } \\
\hline $\begin{array}{l}\text { Yes, Community Guide, } \\
\text { National Prevention Strategy, } \\
\text { or Healthy People } 2020\end{array}$ & 64.0 \\
\hline $\begin{array}{l}\text { No, did not use credible } \\
\text { resource }\end{array}$ & 36.0 \\
\hline
\end{tabular}

Abbreviations: CHIP, Community Health Improvement Plan; LHDs, local health departments. Note: Totals may not add to $100 \%$ due to rounding.

The association between LHD characteristics and presence of at least one evidence-based active transportation strategy in a CHIP is reported in Table 3. After adjusting for other covariates, US LHDs accredited by the Public Health Accreditation Board (odds
Table 2 Proportion of US LHDs With Evidence-Based Active Transportation Strategies Included in a CHIP ( $n=162$ Unweighted; $n=2390$ Weighted)

\begin{tabular}{lc}
\hline Strategies & $\%$ (95\% Cl) \\
\hline $\begin{array}{l}\text { Any evidence-based active } \\
\text { transportation strategies }\end{array}$ & $45.6(37.2-54.3)$ \\
$\quad$ Traffic safety and injury prevention & $19.2(13.2-27.1)$ \\
$\quad$ Traffic-related injury surveillance & $11.0(6.5-17.9)$ \\
and data analysis & \\
Safe Routes to School & $22.3(15.9-30.5)$ \\
Transit access & $19.5(13.6-27.2)$ \\
Mixed-use neighborhoods & $5.7(2.7-11.5)$ \\
$\quad$ Transit-Oriented Development & $4.1(1.7-9.6)$ \\
Smart Growth & $5.7(2.9-10.9)$ \\
Healthy Community design & $20.6(14.5-28.3)$ \\
\hline Abbreviations: CHIP, Community Health Improvement Plan; CI, confidence \\
interval; LHDs, local health departments.
\end{tabular}

ratio $[\mathrm{OR}]=3.67 ; 95 \% \mathrm{CI}, 1.11-12.05)$ and those planning or pursuing accreditation $(\mathrm{OR}=3.40 ; 95 \% \mathrm{CI}, 1.25-9.22)$ were more than 3 times as likely to include at least one evidence-based active transportation strategy in a CHIP compared with LHDs that were not nationally accredited. US LHDs that used a credible resource to select CHIP policy strategies $(\mathrm{OR}=5.25 ; 95 \% \mathrm{CI}, 1.77-15.56)$ or current or past collaboration with $\geq 1$ nonprofit hospital on a Community Health Assessment ( $\mathrm{OR}=4.48$; 95\% CI, 1.23-16.29) were also more likely to include evidence-based active transportation strategies than LHDs that did not use such resources or collaborate with a hospital after adjusting for other covariates.

\section{Discussion}

This national probability survey determined that less than half of LHDs in the US serving $<500,000$ residents participated in the development of a CHIP that included at least one evidence-based strategy supportive of active transportation. The types and proportions of active transportation strategies reported in the current study ranged widely. LHDs pursuing accreditation or accredited by the Public Health Accreditation Board, engaging with at least one nonprofit hospital on a Community Health Assessment, or basing strategies on credible resources were more likely to report any evidence-based active transportation strategy in a CHIP compared with unaccredited LHDs, and LHDs that did not engage in collaboration on a Community Health Assessment and those that did not use a credible resource, respectively.

To our knowledge, this is the first study to document the proportion of evidence-based land use and transportation strategies included in CHIPs nationally. A recent analysis of CHIP documents found a similar proportion (42.4\%) included at least one objective related to access to exercise opportunities, public transportation, and community walkability, but these CHIPs were of LHDs serving all population sizes and accredited by the Public Health Accreditation Board ${ }^{27} \mathrm{~A}$ potential explanation for our finding that less than half of LHD-associated CHIPs included active transportation strategies is that public health officials traditionally report low engagement in built environment decision making, and so, these types of strategies were infrequently included in CHIPs. ${ }^{25,32}$ Transit-Oriented Development and mixed land use neighborhood approaches were among the least reported active transportation strategies included in CHIPs. 
Table 3 US LHDs' Characteristics Associated With Any Evidence-Based Active Transportation Strategies Included in a CHIP ( $n=162$ Unweighted; $n=2390$ Weighted), OR (95\% Confidence Interval)

\begin{tabular}{|c|c|c|}
\hline Characteristics & Crude OR & Adjusted OR \\
\hline \multicolumn{3}{|l|}{ Size of population served } \\
\hline$<25,000$ & Ref. & Ref. \\
\hline $25,000-49,999$ & $1.28(0.50-3.30)$ & $1.15(0.31-4.24)$ \\
\hline $50,000-99,999$ & $2.59(0.99-6.77)$ & $1.44(0.44-4.74)$ \\
\hline $100,000-499,999$ & $1.78(0.68-4.67)$ & $0.58(0.17-1.96)$ \\
\hline \multicolumn{3}{|l|}{ Structure of LHD } \\
\hline Municipal (city or town) health department & Ref. & Ref. \\
\hline County and city-county health department & $2.62(1.05-6.53)^{\mathrm{a}}$ & $0.64(0.13-3.08)$ \\
\hline Other (including state-run and regional) & $4.57(1.09-19.13)^{\mathrm{a}}$ & $1.44(0.23-9.05)$ \\
\hline \multicolumn{3}{|l|}{ State and LHD governance classification } \\
\hline Centralized, shared, or mixed & Ref. & Ref. \\
\hline Decentralized & $0.42(0.17-1.05)$ & $0.31(0.09-1.13)$ \\
\hline \multicolumn{3}{|l|}{ Public Health Accreditation Board accreditation status } \\
\hline Achieved accreditation & $4.81(1.72-13.49)^{\mathrm{b}}$ & $3.67(1.11-12.05)^{\mathrm{c}}$ \\
\hline In progress or planned & $3.75(1.61-8.69)^{\mathrm{d}}$ & $3.40(1.25-9.22)^{\mathrm{e}}$ \\
\hline Not accredited & Ref. & Ref. \\
\hline \multicolumn{3}{|l|}{ Engagement with nonprofit hospitals on a Community Health Assessment } \\
\hline Yes, current or past collaboration with one or more nonprofit hospitals & $5.40(1.98-14.72)^{\mathrm{f}}$ & $4.48(1.23-16.29)^{\mathrm{e}}$ \\
\hline No, current or past collaboration with one or more nonprofit hospitals & Ref. & Ref. \\
\hline \multicolumn{3}{|l|}{ Use of credible resources to guide inclusion of policy strategies in CHIP } \\
\hline Yes, Community Guide, National Prevention Strategy, or Healthy People 2020 & $8.05(3.30-19.64)^{\mathrm{g}}$ & $5.25(1.77-15.56)^{\mathrm{b}}$ \\
\hline No, did not use credible resource & Ref. & Ref. \\
\hline \multicolumn{3}{|l|}{ US census geographic region } \\
\hline Northeast & $0.50(0.20-1.27)$ & $0.26(0.6-1.15)$ \\
\hline South & $1.33(0.51-3.48)$ & $0.37(0.10-1.33)$ \\
\hline West & $0.66(0.27-1.59)$ & $0.50(0.17-1.50)$ \\
\hline Midwest & Ref. & Ref. \\
\hline
\end{tabular}

Abbreviations: CHIP, Community Health Improvement Plan; LHDs, local health departments; OR, odds ratio.

${ }^{\mathrm{a}} P=.04,{ }^{\mathrm{b}} P=0.003,{ }^{\mathrm{c}} P=.03,{ }^{\mathrm{d}} P=.002,{ }^{\mathrm{e}} P=.02,{ }^{\mathrm{f}} P=.001,{ }^{\mathrm{g}} P<.001$.

Two observational studies report that only $5 \%$ of all US municipal jurisdictions had Transit-Oriented Development zoning ${ }^{33}$ and $6 \%$ of all census tracts represent mixed land use neighborhoods, ${ }^{34}$ but neither studied the role of strategic health planning in selecting or adopting these approaches. In 2014, 66.8\% of US municipalities with any type of community plan reported an objective encouraging mixed land use development, which included municipalities serving large populations. ${ }^{17}$ Our finding is somewhat lower, potentially because we surveyed LHDs representing $<500,000$ residents. CHIPs are untapped tools to improve opportunities for PA in communities. Interventions that increase utilization of strategic planning processes among LHDs to address land use and transportation systems require further investigation.

Perceived and objective safety are well-known barriers to active transportation, ${ }^{35,36}$ but a small proportion of LHDs reported CHIPs including strategies related to traffic safety and injury prevention and traffic-related injury surveillance and data analysis. Transportation and public health authorities recommend these approaches as a means to reduce the number of traffic deaths and injuries sustained by pedestrians and bicyclists in the United States, which have been increasing in recent years. ${ }^{36-39}$ These sectors also agree that enhancing the safety of transportation systems and altering built environment require cross-sector collaboration. ${ }^{36-38}$ Case studies highlight collaborations as central to moving transportation-focused and activity-friendly design strategies forward. ${ }^{40}$ CHIPs can generate sustainable solutions by fostering collaborations between sectors to set shared goals, develop accountability, and leverage resources. ${ }^{20}$

Funding and national endorsement of active commuting to school as a public health strategy to reduce child physical inactivity may motivate communities and also explain why Safe Routes to School was the most commonly reported strategy in this study. ${ }^{41,42}$ The prescribed elements of this approach, such as engineering changes to the built environment and equity, overlap with the principles of other less frequently reported strategies, such as Smart Growth. ${ }^{10}$ Communities may consider adopting an active transportation strategy with greater name recognition, such as Safe Routes to School, that generates benefits for all community members through subsequent built environment and safety improvements, as a point of entry for future land use or transportation projects.

Our study documents that accreditation by the Public Health Accreditation Board, use of credible resources, and collaboration with a nonprofit hospital on a Community Health Assessment are important factors for supporting active transportation in a CHIP. These associations are likely driven by the Public Health Accreditation Board accreditation process, which requires a CHIP within 
the past 5 years and recommends including evidence-based strategies selected from resources, such as the National Prevention Strategy, Community Guide, or Healthy People 2020. ${ }^{22}$ A previous survey of US LHDs also linked PA policy/advocacy activities and Public Health Accreditation Board accreditation status. ${ }^{25}$ Another national survey of LHDs found an association between LHD completion of a CHIP and collaboration with a hospital on a Community Health Assessment. ${ }^{43}$ An implication of the current study is that the accreditation process may have a greater impact on selecting evidence-based strategies to improve PA because it sets standards and guidelines for CHIP development that LHDs are required to achieve. ${ }^{22}$

We did not find relationships with several LHD characteristics believed to be important for PA policy processes. Previous literature determined positive relationships between LHD size, structure and governance, and obesity policy/advocacy activities even after adjustment. ${ }^{25,26}$ Our null associations may be an artifact of a small sample size or may suggest that performance improvement characteristics have a stronger impact on active transportation evidencebased decision making than demographic characteristics, such as size of population served. The latter hypothesis is supported by a recent article, which analyzed types of partners described in CHIP documents of nationally accredited LHDs. ${ }^{27}$ Smaller LHDs representing populations fewer than 100,000 residents, which are often described as having fewer resources and less capacity, were more likely than larger LHDs to include each of the partner types assessed (eg, law enforcement, politicians, business, citizens etc). Therefore, the accreditation and simultaneous CHIP development process likely catalyze cross-sector collaborations that bolster the capacity of smaller LHDs making size less of a barrier.

This study includes a number of limitations. Most of the covariates and the outcomes were self-reported and are subject to recall bias. Misclassification of the outcomes and subsequent underestimation of the proportion of LHDs participating in a CHIP with these strategies may have occurred. This was likely nondifferential by exposure covariate status, especially because CHIP documents largely exist in the public domain, and possibly did not affect the associations observed between the covariates and the primary study outcome. It is important to note that communities might be engaged in efforts to improve active transportation through land use and transportation initiatives, but that these were not included in a recent CHIP. We could not adjust for funding, resources, or stakeholders involved in CHIP development because of missing data, which may have resulted in the observed and unobserved relationships between LHD characteristics and our outcomes. The survey used a cross-sectional design, so the relationships cannot be described as causal, but these findings provide preliminary knowledge on a topic that is currently understudied. While selection bias is possible due to a low survey response rate and complete case analysis, a strength of this study is the sensitivity analysis that demonstrated that respondents and nonrespondents and LHDs with missing and complete data were similar with respect to LHD characteristics. Inverse probability weights were also applied to the analysis to account for nonresponse, sampling design, and completion probability.

Strengths of this study include reporting the status of evidencebased active transportation strategies included in CHIPs across the United States and investigating LHD characteristics associated with the inclusion of such strategies. This study also aimed to extend the literature on CHIPs and strategies that promote active transportation at the local level. The findings may be generalizable to US LHDs representing small and medium communities that seek more guidance on evidence-based decision making to promote active transportation.

\section{Conclusions}

Local health departments are increasingly participating in CHIPs, which can provide communities with a method for galvanizing collaboration and building capacity. Such elements are necessary for improving built environments and addressing complex health issues such as physical inactivity. Although our study suggests that less than half of LHDs use this strategic planning process to support active transportation, we also identified possible venues for improvement. For instance, implementing a more popular approach, such as Safe Routes to School, may help soften the ground for other land use or transportation projects. Future research should consider approaches supportive of evidence-based strategic planning, which represents an opportunity for prioritizing active transportation strategies and enhancing physical activity.

\section{Acknowledgments}

The authors would like to thank the local health department officials who participated in the survey. This work is a product of a Prevention Research Center and collaboration with the Division of Nutrition, Physical Activity and Obesity. Support was provided by the CDC (U48 DP005031-05) (C.F. and M.C.R.) and Physical Activity Policy Research Network Plus (U48 DP005031-05S1) (M.S., K.V.G., and S.C.L.). The UMass CCTS (UL1TR001453) and NHLBI/NIH (F31HL142139) (M.S.) provided additional funding. The findings reported are those of the authors and do not represent the official position of the funding institutions. The authors report no conflicts of interest.

\section{References}

1. Dinu M, Pagliai G, Macchi C, Sofi F. Active commuting and multiple health outcomes: a systematic review and meta-analysis. Sports Med. 2019:49(3):437-452. PubMed ID: 30446905 doi:10.1007/s40279018-1023-0

2. Hamer M, Chida Y. Active commuting and cardiovascular risk: a meta-analytic review. Prev Med. 2008;46(1):9-13. PubMed ID: 17475317 doi:10.1016/j.ypmed.2007.03.006

3. McDonald NC, Brown AL, Marchetti LM, Pedroso MS. U.S. school travel, 2009 an assessment of trends. Am J Prev Med. 2011;41(2): 146-151. PubMed ID: 21767721 doi:10.1016/j.amepre.2011.04.006

4. Quinn TD, Jakicic JM, Fertman CI, Barone Gibbs B. Demographic factors, workplace factors and active transportation use in the USA: a secondary analysis of 2009 NHTS data. J Epidemiol Community Health. 2017;71(5):480-486. PubMed ID: 27986862 doi:10.1136/ jech-2016-207820

5. Community Preventive Services Task Force (Task Force). Physical activity: built environment approaches combining transportation system interventions with land use and environmental design. 2016. https://www.thecommunityguide.org/findings/physical-activity-builtenvironment-approaches. Accessed February 28, 2018.

6. Sallis JF, Floyd MF, Rodríguez DA, Saelens BE. The role of built environments in physical activity, obesity, and CVD. Circulation. 2012;125(5):729-737. PubMed ID: 22311885 doi:10.1161/ CIRCULATIONAHA.110.969022

7. United States Department of Transportation. Transit-Oriented Development. 2018. https://www.transit.dot.gov/TOD. Accessed May 17, 2018. 
8. Besser LM, Dannenberg AL. Walking to public transit: steps to help meet physical activity recommendations. Am J Prev Med. 2005; 29(4):273-280. PubMed ID: 16242589 doi:10.1016/j.amepre.2005. 06.010

9. United States Department of Transportation. Transportation and health tool: strategies. 2015. https://www.transportation.gov/mission/health/ strategies-interventions-policies. Accessed February 28, 2018.

10. Safe Routes to School National Partnership. Safe Routes to School: The 6 Es of Safe Routes to School. 2018. https://www.saferoutespartnership. org/safe-routes-school/101/6-Es. Accessed July 16, 2019.

11. Durand CP, Andalib M, Dunton GF, Wolch J, Pentz MA. A systematic review of built environment factors related to physical activity and obesity risk: implications for smart growth urban planning. Obes Rev. 2011;12(5):e173-e182. PubMed ID: 21348918 doi:10.1111/j. 1467-789X.2010.00826.x

12. Centers for Disease Control and Prevention (CDC): National Center for Environmental Health. Healthy places fact sheets: healthy community design. 2016. https://www.cdc.gov/healthyplaces/factsheets. htm. Accessed October 8, 2018.

13. Sallis JF, Spoon C, Cavill N, et al. Co-benefits of designing communities for active living: an exploration of literature. Int J Behav Nutr Phys Act. 2015;12(1):30. doi:10.1186/s12966-015-0188-2

14. Heath GW, Brownson RC, Kruger J, Miles R, Powell KE, Ramsey LT. The effectiveness of urban design and land use and transport policies and practices to increase physical activity: a systematic review. J Phys Act Health. 2006;3(s1):S55-S76.

15. Carlson SA, Paul P, Kumar G, Watson KB, Atherton E, Fulton JE. Prevalence of complete streets policies in U.S. municipalities. J Transp Health. 2017;5(suppl C):142-150.

16. Moore LV, Carlson SA, Onufrak S, Carroll DD, Galuska D. Development and implementation of a local government survey to measure community supports for healthy eating and active living. Prev Med Rep. 2017;6:74-79. PubMed ID: 28271024 doi:10.1016/j.pmedr.2017.02.005

17. Peterson EL, Carlson SA, Schmid TL, Brown DR. Prevalence of master plans supportive of active living in US municipalities. Prev Med. 2018;115:39-46. PubMed ID: 30099046 doi:10.1016/j.ypmed. 2018.08.004

18. Cervero R. Transit-oriented Development in the United States: Experiences, Challenges, and Prospects. Vol 102. Washington, DC: The National Academies Press.; 2004.

19. Goins KV, Schneider KL, Brownson R, et al. Municipal officials' perceived barriers to consideration of physical activity in community design decision making. J Public Health Manag Pract. 2013; 19(3)(suppl 1):S65-S73.

20. Rosenbaum SJ. Principles to consider for the implementation of a community health needs assessment process. The George Washington University School of Public Health and Health Services, Department of Health Policy. 2013. https://nnphi.org/wp-content/uploads/2015/ 08/PrinciplesToConsiderForTheImplementationOfACHNAProcess_ GWU_20130604.pdf. Acessed February 28, 2018.

21. Institute of Medicine (US) Committee on Using Performance Monitoring to Improve Community Health. In: Durch JS, Bailey LA, Stoto MA, eds. Improving Health in the Community: A Role for Performance Monitoring. Washington, DC: National Academies Press (US) Copyright 1997 National Academy of Sciences; 1997. 4, A Community Health Improvement Process. https://www.ncbi.nlm.nih.gov/ books/NBK233012/?report=classic.

22. Public Health Accreditation Board. Standards \& measures (version 1.5). 2014. http://www.phaboard.org/wp-content/uploads/SM-Version1.5-Board-adopted-FINAL-01-24-2014.docx.pdf.

23. National Association of County and City Health Officials (NACCHO). 2016 National Profile of Local Health Departments.
2017. http://nacchoprofilestudy.org/wp-content/uploads/2017/01/MainReport-Final.pdf.

24. Sreedhara M, Goins KV, Aytur SA, et al. Qualitative exploration of cross-sector perspectives on the contributions of local health departments in land-use and transportation policy. Prev Chronic Dis. 2017; 14:E118.

25. Goins KV, Ye J, Leep CJ, Robin N, Lemon SC. Local health department engagement in community physical activity policy. Am J Prev Med. 2016;50(1):57-68. PubMed ID: 26410187 doi:10.1016/ j.amepre.2015.06.033

26. Luo H, Sotnikov S, Shah G, Galuska DA, Zhang X. Variation in delivery of the 10 essential public health services by local health departments for obesity control in 2005 and 2008. J Public Health Manag Pract. 2013;19(1):53-61. PubMed ID: 23169404 doi:10. 1097/PHH.0b013e31824dcd81

27. Kronstadt J, Chime C, Bhattacharya B, Pettenati N. Accredited health department partnerships to improve health: an analysis of community health assessments and improvement plans. J Public Health Manag Pract. 2018;24(suppl 3)Supplement, Impact of Public Health Accreditation:S35-S43.

28. Streiner DL, Norman GR, Cairney J. Health Measurement Scales: A Practical Guide to Their Development and Use. New York, NY: Oxford University Press; 2015.

32. Sosnowy CD, Weiss LJ, Maylahn CM, Pirani SJ, Katagiri NJ. Factors affecting evidence-based decision making in local health departments. Am J Prev Med. 2013;45(6):763-768. PubMed ID: 24237920 doi:10.1016/j.amepre.2013.08.004

33. Association of State and Territorial Health Officials (ASTHO). ASTHO Profile of State Public Health, Volume Three. http://www. astho.org/Profile/Volume-Three/. 2014. Accessed March 7, 2018.

34. Rothman KJ, Greenland S, Lash TL. Modern Epidemiology. 3rd ed. Philadelphia, PA: Lippincott Williams \& Wilkins; 2008.

32. Lemon SC, Goins KV, Schneider KL, et al. Municipal officials' participation in built environment policy development in the United States. Am J Health Prom. 2015;30(1):42-49. doi:10.4278/ajhp. 131021-QUAN-536

33. Thrun E, Leider J, Chriqui JF. Exploring the cross-sectional association between transit-oriented development zoning and active travel and transit usage in the United States, 2010-2014. Front Public Health. 2016;4:113. PubMed ID: 27376054 doi:10.3389/fpubh.2016. 00113

34. Blumenberg E, Brown A, Ralph K, Taylor BD, Voulgaris CT. Typecasting neighborhoods and travelers: analyzing the geography of travel behavior among teens and young adults in the US. University of California, Los Angeles, Institute of Transportation Studies. Report prepared for the Federal Highway Administration; 2015. https:// www.its.ucla.edu/publication/typecasting-neighborhoods-and-travelersanalyzing-the-geography-of-travel-behavior-among-teens-and-youngadults-in-the-u-s/. Accessed June 15, 2018.

35. Buehler R, Götschi T, Winters M. Moving toward active transportation: how policies can encourage walking and bicycling. Active Living Res. 2016:1-8. https://activelivingresearch.org/sites/ activelivingresearch.org/files/ALR_Review_ActiveTransport_January2016. pdf.

36. World Health Organization, Department of Violence and Injury Prevention and Disability. Global Status Report on Road Safety 2013: Supporting a Decade of Action. Geneva, Switzerland: World Health Organization; 2013.

37. National Association of County and City Health Officials. Compendium of NACCHO Policy Recommendations. 2017. https://www. naccho.org/uploads/downloadable-resources/compendiumofpolicy recommendations2017.pdf. Accessed April 3, 2018. 
38. Brookshire K, Sandt L, Sundstrom C, Thomas L, Blomberg R. Advancing pedestrian and bicyclist safety: a primer for highway safety professionals. 2016. (Report No. DOT HS 812 258). Washington, DC: National Highway Traffic Safety Administration.

39. Coleman H, Mizenko K. Pedestrian and Bicyclist Data Analysis: Traffic Safety Facts: Research Note. United States. National Highway Traffic Safety Administration; 2018.

40. Baker EA, Wilkerson R, Brennan LK. Identifying the role of community partnerships in creating change to support active living. Am J Prev Med. 2012;43(5)(suppl 4):S290-S299. PubMed ID: 23079261 doi:10.1016/j.amepre.2012.07.003

41. Safe Routes to School National Partnership. Safe Routes 101: Funding History of Safe Routes to School. 2018. https://www. saferoutespartnership.org/healthy-communities/101/history. Accessed June 15, 2018.

42. US Department of Health and Human Services ODPHP. Healthy people 2020: physical activity. 2016. https://www.healthypeople. gov/2020/topics-objectives/topic/physical-activity/objectives. Accessed June 15, 2018.

43. Singh SR, Carlton EL. Exploring the link between completion of accreditation prerequisites and local health departments' decision to collaborate with tax-exempt hospitals around the community health assessment. J Public Health Manag Pract. 2017; 23(2):138-147. PubMed ID: 27598711 doi:10.1097/PHH. 0000000000000409 


\section{Erratum: Sreedhara et al. (2019)}

In the original publication of this article, the copyright was assigned to Human Kinetics, Inc. The authors subsequently obtained Open Access distributed under the terms of the Creative Commons Attribution License CC BY NC ND 4.0, which reverted copyright back to the authors. This was corrected and updated in the online version of the article. 